\title{
Construction of Flipped Classroom Education Model in Colleges and Universities Based on MOOC
}

\author{
Dingyu Song \\ Department of educational affairs of Nanyang Institute of Technology, Nanyang, Henan, 473000
}

Keywords: MOOC; education model; flipped classroom

\begin{abstract}
MOOC gradually attacks traditional classroom teaching with its advantages of high quality resources, abundant forms of teaching, convenient learning, and strong interaction. Based on the characteristics and advantages of MOOC and flipped classrooms, this paper discusses the teaching practice of MOOC-based classroom teaching. The presentation of the classrooms provides MOOC with room for growth combined with physical classrooms. Flipped classroom reinterprets the new forms of "teaching" of teachers and "learning" of students.
\end{abstract}

\section{Introduction}

With the rapid development of the application of information technology in the field of education at home and abroad, higher education is facing the challenge and impact from the Internet, and it also breeds many opportunities for development. The new concept of education and teaching has been continuously introduced. The traditional inefficient teaching model has undergone subversive reforms, and new forms of education have emerged. Especially with the success and popularity of the "Khan Academy" model on a global scale, the Flipped Class Teaching Method has rapidly entered the academic field of vision, which has aroused the attention of the academic community and considered it as a subversive innovation in the traditional classroom teaching model. . Against this background, China's Ministry of Education has also taken a series of important promotion measures. From the video open class and the construction of network resource sharing courses to the "micro-curriculum contest" covering the whole country, it is necessary to promote the depth of domestic higher education and information technology. Integration, ultimately achieving online education and teaching in a larger range.

\section{Status of Large-scale Open Web Courses}

A large open web course, MOOC (Massive Open OnlineCourses). In 2012, the top universities in the United States successively set up online learning platforms and provided free courses on the Internet. The rise of course providers such as Coursera, Udacity and edX has provided more students with the possibility of systematic study. Under the background that foreign MOOCs are in full swing, Hong Kong University, Peking University, Tsinghua University and other famous universities have all invested heavily in open education online. Currently, Peking University and Tsinghua University have joined edX, one of the three major MOOC organizations. Fudan University and Shanghai Jiaotong University have joined Coursera. The Ministry of Education of the People's Republic of China cooperated with NetEase's open class and launched a large-scale MOOC online teaching platform with the help of the "Love Course" network. Domestic elite schools have established courses on their platforms. Similar domestic online education platforms are also emerging, such as the MOOC website of MOOC at Tsinghua University. Although there is a good start, MOOC has encountered bottlenecks in its development in China. 1. The MOOC curriculum model has a lack of management and control over students' learning. The loss of trainees is very serious. From the point of view of course activities, MOOCs are almost a complete autonomous learning process. The motivation for learning is spontaneously generated and maintained by students. Many students find it difficult to adhere to the end of the course for a variety of reasons, causing a large number of students to lose. The basic reason is that teachers and 
teaching management and platform management have no control over the student's learning process, and students' learning behavior basically depends on student self-consciousness, interest, and self-control ability. 2. Problems with the MOOC Education Platform First of all, some universities in China cannot correctly handle the relationship between exquisite classes, quality resource sharing classes, video open classes, and open online courses. They believe that putting online teaching videos on the Internet for students to browse is online education. Form a misunderstanding. Secondly, most teachers in China are accustomed to the classroom teaching mode of chalk plus blackboard, PPT plus projector, and they are not suitable for the form of online teaching. As a result, most teachers' information technology application level is not high, and they do not have the information literacy needed to control online teaching, and some excellent teachers cannot use the information technology to develop online teaching. Thirdly, the production of MOOC courses requires professional production teams and demanding video production equipment. Not all institutions have sufficient funds to plan for construction. Even with such teams and equipment, the demand for large-scale curriculum construction cannot be met. Therefore, after many colleges and universities introduced several representative MOOC courses, the follow-up courses were slow.

\section{Flipped Classroom Teaching Mode}

Flipped Classroom or Inverted Classroom Other interpretations include reversed classroom or reversed classroom, formally proposed since 2000 and initially formed in 2011. American educators have always been committed to defining it. In 2011, the flipping classroom held in the State of Colorado in the United States gave a more comprehensive explanation of the meaning of flipping the classroom. The consensus of the meeting was mainly as follows: Turning the classroom is a means to use information technology as a carrier of knowledge transfer to increase the time for effective communication and interaction between students and teachers. It also conforms to the personalized needs of education and can create an environment for personalized learning. Effectively improve students' learning enthusiasm and reconstruct the learning process. In his dissertation, Chen Xiaofei defines the flipping classroom teaching model as follows: Relying on information technology, making teaching videos through education technology enables students to complete knowledge acquisition before class and teachers provide opportunities to provide students with opportunities for collaborative learning and communication. Help students realize the internalized learning of knowledge, thereby affecting the student's learning environment, and making students become true masters of learning a new type of teaching model. It is regarded as a new type of teaching that subverts the traditional classroom teaching mode. It records the basic knowledge of the course as a series of well-made, concise and clear teaching videos. Students learn basic knowledge and basic principles through video learning after class. In the classroom, it mainly realizes the internalization of knowledge. The main forms can be discussions, joint operations, and experiments. "Learning outside, studying inside" is a refined interpretation of the "flipping classroom" teaching model. With the rapid development of modern information technology, the production and dissemination of lecture materials, the acquisition and feedback of learning information, and the study of learning effects are becoming more and more convenient, and they also provide more choices for the implementation of flipped classrooms. Microclass video, online courses, social software, etc. can all be used to flip classroom technical means. Open online courses are used as a technical means to flip the classroom.

\section{Advantages of Flipped Classroom Mode Based on Online Course Platform}

The flipping classroom teaching model based on the online course platform can effectively compensate for the phenomenon of out-of-control in the teaching process of the MOOC teaching model, so that the teacher can truly become the organizer, leader and facilitator of the course. Effective monitoring of teaching progress and teaching effectiveness can be implemented to increase students' interest in the course, improve student participation, and ensure the effectiveness of the entire course. The complete online course is only the electronic learning materials on the 
Internet, lack of realistic feeling and sufficient communication links. By turning over the classroom, you can make up for these deficiencies. In the flipping classroom, hands-on experiments, lectures, discussions, melodrama performances and other teaching sessions can be conducted, and the quality and ability of these links can not be achieved by online means. Through a unified flipping of the classroom platform, it is beneficial for the teaching unit to deploy the task of curriculum construction in a unified manner and to implement training for teachers to facilitate large-scale construction. At the same time, based on the curriculum platform of the overturned classroom, the objectives are not large and comprehensive, and the most cost-effective technology solutions can be adopted. The most convenient recording technology is adopted to improve the efficiency of curriculum construction, greatly reduce construction costs, and establish large-scale promotion advantages.

Unlike uploading videos to public video sites, teaching materials are based on a dedicated curriculum platform that can carry a wealth of curriculum information, can communicate and interact in various ways, can be flexibly adjusted according to the progress of the curriculum, and control the uploading of learning materials. By modifying and revoking, students can achieve $7 * 24$ hours of study around the clock. Through a dedicated curriculum platform and quizzes in class, teachers can promptly understand the students' learning situation, adjust the content of the courses according to the students' mastery of the situation, and focus on general issues and provide targeted guidance on individual issues. In this Internet age, teaching methods must also keep pace with the times and make full use of the convenience advantages that the Internet brings to education and teaching. Through comparative research, there are indeed a series of problems in the MOOC teaching platform, but it has brought teaching into a completely new field-flipping classrooms. Although this teaching model is not yet available on a large scale, its development prospects are very optimistic. .

\section{Implementation of MOOC-based Flipped Classroom}

The flipping classroom teaching is task-driven teaching based on constructivist theory of the theory of learning. Its teaching process is teaching teachers to record teaching video materials, students self-study, teachers in class, interactive discussion, and then achieve good learning results. (1) Course development. The initial work of flipping the classroom is for teachers to carry out curriculum development, mainly recording teaching videos, audio, documents, PPT, etc. For these contents, teachers will do a lot of work to make the camera not nervous and teach nature, the course content is proficient, No error, etc. It is a precondition for the success of the classroom. Therefore, it is necessary to do a good job of designing the teaching in advance. It is best to organize related teachers, form teams, and fix the template for lesson plans. The modules are jointly developed. (2) Data push. The course materials are placed on the MOOC learning platform before the class, which is mainly focused on explaining videos and matching exercises so that learners can learn in advance. Learners can freely and autonomously grasp the learning process and find problems and solve problems in the process of understanding knowledge. (3) Learners know themselves. During the learner's learning process, the MOOC platform continuously records learners' learning time, trajectory and other information. Learners can not only see their own learning time, completion progress and other information, but also can see the peer's learning information, invisible incentives. Learner's learning. In this process, teachers should strengthen interaction and reminders, and they can add some discussion about the difficulties of knowledge to prevent learners from encountering difficulties and unable to continue learning. (4) Teacher guidance. After the students conduct self-study before class, they will be grouped and explained in the class. The students will become teachers. During the group's explanation, other group members can ask questions and discuss, achieve collaboration within and between groups, and teachers can make personalized comments and guidance. answer. In overturning classroom teaching, teacher guidance is particularly important. It is necessary to distinguish between the content taught in online teaching and content under the title line. Therefore, teachers need to design the teaching "package" in advance and timely "shake bag” for students. Learn to guide it properly. Course development stage. Teaching video recording 
can use professional video cameras or home DV. If the teacher himself does not show up, he can use some recording software (such as Adobecaptivate) plus a tablet, and later use Pre-miere and other video editing software to edit and insert PPT and other materials into the video. in. Can use Crazytalk, Crazytalkanimator and other software, to class

\section{Conclusion}

The MOOC-based rollover classroom is a new type of teaching model. It requires teachers to do a lot of preparatory work in the early stages. It also requires the students to spend a lot of time to study, which is more suitable for a relatively small number of classes. In the classroom, teachers' role change is very important. Teachers become leading scholars. Teachers need to handle the differences between online and offline teaching courses and really do effective teaching. It is not difficult to implement the flipping classroom, and it has very broad application prospects. If relevant companies or team-assisted teachers develop curriculums to form normalization, more and more teams will join the flipping classroom, flipping classrooms in education and teaching. The application will also be more extensive and in-depth.

\section{References}

[1] Li Zhimin. The rise of "Music Lessons" led to the awakening of Chinese universities [J]. China High Education, 2014(7):30-33.

[2] Chen Xi, Gao Yu. MOOC Course Model and Its Impact on High Schools [J]. Software Guide, 2014(1):12-15.

[3] Everything is wonderful. The application of MOOC-based flipping classroom in college teaching [J]. Software Guide, 2014(9): 189-191.

[4] Zhang Jinlei, Wang Ying, Zhang Baohui. Flip classroom teaching model research [J]. Distance Education Journal, 2012(4):46-51.

[5] Zhu Hongjie, Zhu Wei. Turning over the classroom and its effective strategy and strategy [J]. Electro-Education Education Research, 2013(8): 79-83 